\title{
Professional codevelopment groups for the promotion of nursing research in clinical settings
}

\author{
Marilyn Aita ${ }^{* 1,2}$, Marjolaine Héon ${ }^{1}$, Annie Lampron ${ }^{1}$, France Dupuis ${ }^{1,2}$, Sylvie Le May ${ }^{1,2}$ \\ ${ }^{1}$ Faculty of Nursing, University of Montreal, Montreal, Canada \\ ${ }^{2}$ Sainte-Justine University Hospital Research Center, Montreal, Canada
}

Received: July 25, 2014

Accepted: October 27, $2014 \quad$ Online Published: November 16, 2014

DOI: $10.5430 /$ jnep.v5n1p137

URL: http://dx.doi.org/10.5430/jnep.v5n1p137

\begin{abstract}
The active participation of nurses in research activities is desirable in clinical settings. This manuscript highlights the Professional Codevelopment Groups (PCGs) as an opportunity for clinical nurses to be the leading instigators of research projects relevant to their nursing practice, emphasizing another facet of their professional role in clinical settings.
\end{abstract}

Key Words: Professional codevelopment group, Clinical settings, Nursing research, Clinical nurses, Nurse scientists

\section{Introduction}

It is widely acknowledged that research is a key element of nursing science that has the potential to improve care ${ }^{[1]}$ and to ensure that nursing interventions are safe, efficient and health-enhancing. ${ }^{[2]}$ Clinical nurses hold a strategic position to raise relevant research questions, ${ }^{[3]}$ which is why their active participation in research activities is generally regarded as desirable. ${ }^{[4,5]}$ Although the implementation of a research culture in clinical settings is clearly beneficial for the practice, experience and research have shown that a change at that level is a complex process involving many actors, of whom managers seem to be one of the most important groups. ${ }^{[6,7]}$ Indeed, they play a fundamental role in supporting the positive attitudes of clinical nurses towards research, as well as to manage and plan research activities in clinical settings. ${ }^{[8]}$

In this perspective, several activities involving clinical nurses and managers, such as reflective practice groups, journal clubs, and communities of practice have been imple- mented in clinical settings. These activities aimed at refining the clinical practice may be efficient to promote professional knowledge on an individual or group basis. Besides, the Professional Codevelopment Groups (PCGs) are another type of activity that can facilitate the development of a nursing research culture. This approach has the added value of allowing clinical nurses to play a concrete and active role in conducting research projects. Compared to other types of activities, the PCGs are a strategic approach combining the learnings from an individual and a group perspective where each can improve its professional research practice with the analysis of situations experienced by others. ${ }^{[9]}$ Therefore, the approach of the PCGs is an effective way for clinical nurses to share and gain knowledge through interpersonal relationships, all the while reinforcing individual skills. ${ }^{[10]}$ Given their coordination skills, their ability to work in multidisciplinary contexts and their privileged position to collect patient data, all research teams can benefit from the expertise of clinical nurses. However, clinical nurses need significant support from their managers, such as coaching and protective time, in order to pursue their research activ-

\footnotetext{
*Correspondence: Marilyn Aita; Email: marilyn.aita@umontreal.ca; Address: Faculty of Nursing, University of Montreal, 2375 Côte SainteCatherine, Montreal, Quebec, H3T 1A8, Canada.
} 
ities, to actively participate in research projects, ${ }^{[7]}$ and to implement PCGs in clinical settings. Therefore, the purpose of this manuscript is to describe the values of PCGs as a strategy to foster research activities amongst clinical nurses. The PCGs, its theoretical bases and definition, along with its form of group-organization and operationalization are first presented, followed by comparisons of the PCGs' objectives and organization with other group-learning methods. Finally, we describe how actual implementations of this strategy had positive effects in promoting research activities in a clinical setting.

\section{Professional codevelopment groups}

Developed in Quebec (Canada) in the early 1980s, the PCGs are a training approach based on learning community principles, and was originally intended to improve the management of professional practice. ${ }^{[9]}$ Since then, the approach has evolved to include academic activities. ${ }^{[9-17]}$ PCGs rely on intragroup interactions, ${ }^{[9]}$ promoting theory and knowhow, as well as interpersonal skills and self-awareness. ${ }^{[18]}$

In the term "codevelopment", the concept of development refers to the learning process and to the improvement of professional competencies, whereas the prefix "co" emphasizes the social dimension of this learning process. ${ }^{[9]}$ Since it has been shown that socialization is effective in reducing the gap between practice and research, ${ }^{[3]}$ there is a strong indication that the PCGs approach would be well-suited for the tasks of establishing and nurturing research-based practice.

\subsection{PCGs organization and operationalization}

PCGs should be composed of four to "ten professionals who participate on a voluntary basis and who benefit from organizational support. It is recommended that the group meet every second to five weeks, for about three to four hours, and for a period varying between six to twelve months. ${ }^{[9]}$ This being said, each group is free to schedule the frequency and duration of meetings according to their particular needs. The PCGs are generally composed of a facilitator and participants who alternatively play the role of clients (learner) and consultants in a five-step process. The facilitator leads the meetings, facilitates the discussion, and supports the members of the group in achieving their objectives. ${ }^{[9]}$ The role of the facilitator is not to teach or solve a problem as an expert, but to help the other professionals to learn and think by themselves and explore possible solutions to their problems. Throughout the group meetings, the client presents issues related to his/her own project ${ }^{[9]}$ to the other participants. Other participants are then required to act as consultants to support the member who shared his/her experience, thoughts and concerns. During the second step, the consultants and the facilitator ask questions and validate that they have clearly identified the problem and, if required, clarify missing elements. The third step requires that the client defines the consultation contract to be approved by consultants. In the fourth step, members synthesize and integrate the information shared throughout the discussion and use it to progress further. In the fifth step, a plan detailing what needs to be accomplished before the next group meeting is devised by the client with the help of the consultants. Finally, the client and the consultants brainstorm on their own learning process. In brief, the PCGs are similar to an action group training where a project manager and members meet on a regular basis to discuss and learn from the issues encountered by all parties. ${ }^{[16]}$

As a mean to promote the sharing of experiences, the PCGs offer participants the opportunity to reflect individually and in collaboration about the improvement of professional practice. ${ }^{[9]}$ This approach adapts well to the characteristics of both participants and their environment, and requires no complex procedures. ${ }^{[19]}$ According to Payette, ${ }^{[20]}$ approaches requiring a genuine involvement from participants, such as the PCGs, have the greatest impact on practice change.

\subsection{PCGs compared to other group learning meth- ods}

The PCGs organization and operationalization may appear to be similar to other common group learning methods such as reflective practice groups, journal clubs, and communities of practice. Yet, even if these groups share the common goal of promoting research and evidence-based practice, there are differences regarding their objectives and organization (see Table 1).

Table 1: Comparisons of PCGs to other group learning methods

\begin{tabular}{|c|c|c|}
\hline & Objectives & Organization \\
\hline $\begin{array}{l}\text { Reflective } \\
\text { practice groups }\end{array}$ & $\begin{array}{l}\text { To describe, analyze and evaluate } \\
\text { experiences encountered in } \\
\text { clinical practice. }\end{array}$ & $\begin{array}{l}\text { Individually } \\
\text { or in group }\end{array}$ \\
\hline Journal clubs & $\begin{array}{l}\text { To analyze research articles to } \\
\text { promote the implementation of } \\
\text { research findings in practice. }\end{array}$ & Group \\
\hline $\begin{array}{l}\text { Communities of } \\
\text { practice }\end{array}$ & $\begin{array}{l}\text { To solve problems related to the } \\
\text { discipline and share expertise. }\end{array}$ & Group \\
\hline PCGs & $\begin{array}{l}\text { To benefit from the support of } \\
\text { coworkers in the development and } \\
\text { implementation of individual or } \\
\text { common research projects through } \\
\text { structured consultations. }\end{array}$ & Group \\
\hline
\end{tabular}

\subsubsection{Reflective practice groups}

The reflective practice groups use a similar organizational structure as the PCGs, but the latter differs in that all participants are actively implicated in the analysis and the problem-solving of a situation linked to clinically-relevant research. The reflective practice is a process in which experiences encountered in clinical practice are described, an- 
alyzed and evaluated on an individual basis ${ }^{[21]}$ but can also be performed in groups. In group sessions, participants have the possibility to share reflections about a clinical experience and enlighten their practice with theory. ${ }^{[22,23]}$

\subsubsection{Journal clubs}

The emergence of journal clubs in clinical settings was mainly motivated by the purpose of exposing nurses to research literature and promote evidence-based practice. ${ }^{[24]}$ Through journal clubs, nurses can help each other understand and criticize scientific research papers. ${ }^{[25-27]} \mathrm{Al}-$ though this group learning method is widely implemented in clinical settings to promote nursing research and reduce barriers to research utilization, ${ }^{[28]}$ they mainly differ from the PCGs by their objectives. For instance, the main objective of journal clubs is to analyze research articles to promote the implementation of research findings in practice, whereas the PCGs can share some of the objectives related to actual research being carried out in the clinical settings. These objectives may be to identify the research problem, write the research question, design and implement the research methods, and even assess the feasibility and acceptability of research interventions.

\subsubsection{Communities of practice}

In communities of practice, professionals are required to help each other solve problems specific to their discipline $^{[29,30]}$ and share expertise. ${ }^{[31]}$ It is also a mean to promote clinical nursing research. ${ }^{[32]}$ The communities of practice offer an infrastructure built upon interactions between professionals that may take place virtually. Although, this training strategy differs from the PCGs in one significant respect: the communities of practice are characterized by a shared agenda, ${ }^{[32]}$ interest, motivation and values, ${ }^{[33]}$ whereas in PCGs each participant leads his/her own project.

Finally, the PCGs are a learning approach that can offer nurses the opportunity to benefit from the support of their coworkers in the development and implementation of their individual or common research projects through structured consultations. The interactions within the group act as a powerful catalyst ${ }^{[9]}$ for the development of each participant's research capacities.

\section{Experience and outcomes related to the implementation of PCGs in a clinical set- ting}

At CHU Sainte-Justine Mother and Child University Hospital Center, in Montreal (Canada), there was a genuine desire from nursing managers to promote nursing research in the clinical setting. Achieving this goal was mainly driven by the beliefs that clinical nurses should be involved in projects to enhance their interests in research, to develop new skills, and to improve the quality of care provided to clients. To

Published by Sciedu Press reach this objective, the managers have facilitated the implementation of several strategies, including the PCGs which were introduced in 2009.

Three PCGs were created and involved clinical nurses, clinical nurse specialists and nurse scientists. Each group had their own specific theme of interest, but each group had similar objectives and learning processes. The participating clinical nurses were either interested in developing a research project or write a scientific paper. With the support of the nurse scientists and other nurse consultants, they developed their own individual projects.

The organization of these groups was facilitated by a nursing research coordinator (Managers who wish to promote nursing research in their clinical setting and do not benefit from the services of a research coordinator could also be the instigators of the PCGs). One of her roles was to provide leadership in identifying and implementing ways to promote nursing research and practice based on scientific evidence. The coordinator invited clinical nurses and clinical nurse specialists who showed an interest in nursing research to participate to the PCGs. She presented the outlines of the teaching approach and prepared a document describing the purpose, objectives and activities related to the PCGs. She then recruited nursing researchers from the Faculty of Nursing of the University of Montreal who agreed to host the group meetings and support nurses throughout their efforts.

The three PCGs at Sainte-Justine distinguished themselves by their scientific orientations (see Table 2). Firstly, the participants in group 1, whose themes were related to family, education and knowledge transfer, pooled their research ideas to develop a joint project on the validation of a systemic family nursing intervention to support families with adolescents with a chronic health problem. In 2011, this research project was funded by the Foundation for Nursing Research of Quebec (FRESIQ) and was awarded the MarieFrance Thibaudeau prize attributed to promote the dissemination of nursing research. The participants in group 2 gathered under the themes of clinical application, journal club and emergency care services. Their efforts were mainly invested in the publication of a scientific article. ${ }^{[27]}$ Members of group 3 involved nurses with an expertise in perinatal or neonatal care. The group activities were dedicated to the critical analysis of scientific articles in order to promote the development of clinical research projects.

The experiences of PCGs at Sainte-Justine's reflect some conditions of success and difficulties identified by Payette and Champagne. ${ }^{[9]}$ First, the clinical nurses involved in these groups showed good motivation since their commitment was on a voluntary basis. They identified significant clinical problems, which were discussed and studied among the PCGs, creating thereby a trusting relationship among the group. To ensure the sustainability of the PCGs in clinical settings, the motivation of all clients should be maintained 
and their competencies must be strategically exploited by the facilitator to sustain their participation. Each group had a different scope depending on the context, needs and availability of the clinical nurses and nurse scientists participating. Although the ultimate goal was to develop research projects, meetings led to different types of projects related to the progression of research (see Table 2). The groups had to contend with the inherent clinical issues such as the withdrawal of participants, changes in professional positions along with the decreased availability and increased obligations inherent to a nursing shortage context. Man- agement support was essential for the participants to benefit from protective time for group meetings and to ensure sustainability in line with political and organizational contexts. Time restrain is one of the most frequent issues in implementing and maintaining PCGs in clinical settings. ${ }^{[9]}$ Therefore, managers are accountable to promote an environment supporting research and encouraging clinical nurses' participation in research activities by allowing protective time, all contributing to a research-based culture environment in clinical settings. ${ }^{[8]}$

Table 2: Orientation of PCGs

\begin{tabular}{|c|c|c|c|}
\hline & Group 1 & Group 2 & Group 3 \\
\hline Themes & $\begin{array}{l}\text { Family, teaching, knowledge } \\
\text { transfer }\end{array}$ & $\begin{array}{l}\text { Clinical application, } \\
\text { journal club, emergency care }\end{array}$ & $\begin{array}{l}\text { Labour, lighting in neonatal } \\
\text { intensive care unit (NICU) }\end{array}$ \\
\hline Types of projects & $\begin{array}{l}\text { Development of a research project } \\
\text { funded by the FRESIQ and } \\
\text { awarded by the Marie-France } \\
\text { Thibaudeau prize }\end{array}$ & $\begin{array}{l}\text { Publication of a scientific article } \\
\text { (Sauvé et al. 2009) and } \\
\text { identification of nurses' needs to } \\
\text { develop a research project }\end{array}$ & $\begin{array}{l}\text { Development of abilities to } \\
\text { understand and analyze scientific } \\
\text { research articles }\end{array}$ \\
\hline
\end{tabular}

\section{Conclusion}

The PCGs are a promising approach to promote nursing research in clinical settings and to generate scientific knowledge that improves clinical care. Indeed, the implementation of the PCGs in a clinical setting has led to the development of a research project aiming at validating a systemic family nursing intervention to support families with adolescents diagnosed with a chronic health problem. By involving nurses in the first steps of the project, as well as the formulation of the research questions, this study was a good trigger for these nurses in considering some practice changes for this clientele. To reinforce the value of PCGs in clinical settings, further research should concentrate on evaluating the effect of this activity on outcome in practice and compared it to the other learning methods such as reflective practice groups, journal clubs and communities of practice.

The collaboration between clinical nurses, nurse scientists, and managers in PCGs also facilitates sharing of research knowledge and skills. The participation of clinical nurses in research reinforces the connexions between the clinical and the academic spheres and promotes the integration of knowledge into practice. On the one hand, researchers support clinical nurses in developing their research skills, and on the other, clinical nurses provide researchers with knowledge about the reality of practice in clinical settings and inform them of issues of interest for the development of research protocols. Finally, it is crucial to note that the involvement of managers in supporting members (i.e. clients, consultants, etc.) composing the PCGs is essential for the creation and sustainability of PCGs in clinical settings.

\section{Acknowledgements}

The authors would like to acknowledge the support of Mrs. Louise Robinette, RN, MSc., Assistant Director of Nursing at CHU Sainte-Justine Mother and Child University Hospital Center, for her comments on a previous version of this manuscript. We would also like to express our appreciation to all the nurse clinicians and clinical nurse specialists who participated to the PCGs. This article was published in French under the following reference: Aita, M., Lampron, A., Héon, M., Dupuis, F., \& LeMay, S. (2013). Les groupes de codéveloppement professionnel. Une approche d'apprentissage qui arrime recherche et pratique clinique. Perspective infirmière, 10(4), 31-34.

\section{Conflicts of Interest Disclosure}

The author declares that there is no conflict of interest statement.

\section{References}

[1] Happell, B. The centre for psychiatric nursing research and practice: An innovative approach to enhancing clinical nursing research in the psychiatric/mental health field. Issues Ment Health Nurs. 2004; 25: 47-60. PMID:14660316 http://dx.doi.org/10.1080/016 12840490249028-23

[2] Forbes, A. Clinical intervention 2014 research in nursing. Int J Nurs Stud. 2009; 46: 557-568. PMID:18930228 http://dx.doi.org 
/10.1016/j.ijnurstu.2008.08.012

[3] Burns, S.M. Clinical research is part of what we do: The experience of one medical intensive care unit. Crit Care Nurse. 2002; 22(2): 100-113. PMID: 11961932

[4] Fitzgerald, M., Milberger, P., Tomlinson, P.S., Peden-McAlpine, C., Meiers, S.J., Sherman, S. Clinical Nurse Specialist Participation on a Collaborative Research Project. Barriers and Benefits. Clin Nurse Spec. 2003; 17(1): 44-49. PMID:12544120 http://dx.doi.org /10.1097/00002800-200301000-00020

[5] Polit, D.F., Hungler, B. P. Nursing Research: Principles and Methods (6th ed.). Philadelphia: Lippincott; 1999. PMID:10482253

[6] Fixen, D.L, Naoom, S.F., Blasé, K.A., Friedman, R.M, Wallace, F. Implementation Research: A Synthesis of Literature. Tampa, Florida: Louis de la Parte Florida Mental Health Institute Publication; 2005

[7] Rycroft-Malone, J., Bucknall, T. Models and frameworks forimplementing evidence based-practice: Linking evidence to action (Eds.) West Sussex, UK: Wiley-Blackwell; 2010.

[8] Akerjordet, K., Lode, K., Severinsson, E. Clinical nurses' attitudes towards research, management, and organisational resources in a university hospital: part I. J Nurs Manag. 2012; 20: 814823. PMID:22967299 http://dx.doi.org/10.1111/j.1365-2 834.2012.01477.x

[9] Payette, A., Champagne, C. Le groupe de codéveloppement professionnel (1st Ed.). Quebec: Presses de l'université du Québec; 1997.

[10] Aita, M., Richer M.-C., Héon, M. Illuminating the Processes of Knowledge Transfer. Worldviews Evid Based Nurs. 2007; 4(3): 146-155. PMID:17850495 http://dx.doi.org/10.1111/j.1 741-6787.2007.00087.x

[11] Arsenault, G. et Y. Poulin. « Le codéveloppement à l'Institu Philippe-Pinel», Interactions - Psychologie des relations humaines. 2001; 5(2): 54-64.

[12] Garceau. M. L'expérience des cercles de gestion à la Fonction publique fédérale. Interactions - Psychologie des relations humaines. $2001 ; 5(2)$ : 67-74.

[13] Laurin, J-C. Le Réseau-Défi, une expérience de codéveloppement interentreprises. Interactions - Psychologie des relations humaines. 2001; 5(2): 95-98.

[14] Mercure, C. Des groupes de codéveloppement interétablissement dans la région de Laval. Interactions - Psychologie des relations humaines. 2001; 5(2): 75-84.

[15] Lafranchise, N., Lafortune, L., Rousseau, N. Insertion professionnelle, émotions, compétence émotionnelle et accompagnement des personnes enseignantes. Actualité de la recherche en éducation et en formation. 2007

[16] Payette, A. Le groupe de codéveloppement et d'action-formation. Effectif -Le magazine de l'ordre des conseillers en relations industrielles du Québec. 2000; 3(2): 30-35.

[17] Ricard, D. L'apprentissage-action dans un contexte universitaire au Québec. Interactions - Psychologie des relations humaines. 2001; 5(2): 131-144.

[18] Morin, É. Le codéveloppement: comment apprendre en travaillant! Capital humain FRP Groupe Conseil. 2004; 10(2). Avail- able from: http://www.aliaconseil.com/File/bulletin/ novembre_2004.pdf

[19] Courbron, M. Le codéveloppement professionnel... une approche maintenant adaptée à notre pratique. En pratique. 2006; 6: 9-11.

[20] Payette, A. Le codéveloppement professionnel : une intuition qui se développe sans cesse. Sources ENAP 2000b; 15(may-june): 6-7.

[21] Reed, B. But we're doing it already! Exploring a response to the concept of reflective practice in order to improve its facilitation. Nurse Educ Today. 1993; 13(4): 305-309. http://dx.doi.org /10.1016/0260-6917 (93) 90058-A

[22] Bailey, M.E., Graham, M.M. Introducing guided group reflective practice in an Irish palliative care unit. Int J Palliat Nurs. 2007; 13(11): 555-560. PMID:18073703 http://dx.doi.org/10.12 968/ijpn.2007.13.11.27591

[23] McGrath, D., Higgins, A. Implementing and evaluating reflective practice group sessions. Nursing Educ Pract. 2006; 6: 175181. PMID:19040874 http://dx.doi.org/10.1016/j.nepr. 2005.10 .003

[24] Campbell-Fleming, J., Catania, K., Courtney, L. Promoting evidenced-based practice through a traveling journal club. Clin Nurse Spec. 2009; 23(1): 16-20. PMID:19098510 http://dx.d oi .org/10.1097/01. NUR.0000343077.73085.91

[25] Kleinpell, R. M. Promoting research in clinical practice: Strategies for implementing research initiatives. AACN Adv Crit Care. 2008; 19(2): 155-161. PMID:18560283 http://dx.doi.org/10.1097 /01.AACN.0000318117.82308.8d

[26] Marcil, I., Goulet, C. Le « Journal Club » : un outil pour l'utilisation de la recherche dans la pratique infirmière. L'infirmière du Québec. 2009; 9(5): 46-51.

[27] Sauvé, C.C., Hogue, A., Lampron, S., Le May, S., Canuel, A. Un club de lecture à l'urgence, une stratégie pour promouvoir la pratique basée sur les résultats probants. Première Ligne. 2009; 23(2): 14-21.

[28] O'Nan, C. L. 2011. The effect of a journa club on perceived barriers to the utilization of nursing research in a practice setting. $\mathrm{J}$ Nurses Staff Dev. 2001; 27(4): 160-164. PMID:21788742 http: //dx.doi.org/10.1097/NND.0b013e31822365f 6

[29] Dubuc, S. Lancement d'une communauté de pratique pour des infirmières spécialisées en soins d'urgence. Première ligne. 2008; 22(1): 26-27.

[30] Wenger, E., McDermott, R. Snyder, W. Cultivating communities of practice. A guide to managing knowledge (Eds.). Boston: Harvard Business School Press; 2002.

[31] Wenger, E. C., Snyder, W.M. Communities of practice: the organizational frontier. Harvard Bus Rev. 2000; 139: 145.

[32] Short, A., Jackson, W., Nugus, P. Expanding clinical research capacity through a community. Nurse Educ Pract. 2010; 10(1): 5256. PMID:19427268 http://dx.doi.org/10.1016/j.nepr. 20 09.03 .016

[33] O’Donnell, D., Porter, G., McGuire D., Garavan, T.N., Heffernan, M. Cleary P. Creating Intellectual Capital: A Habermasian Community of Practice (CoP) Introduction. J Eur Ind Train. 2003; 27(2/3/4): 80-87. 